\title{
ORGANIC ACID LIGNIN FROM RICE STRAW IN PHENOL-FORMALDEHYDE RESIN PREPARATION FOR PLYWOOD
}

\author{
SHRIKANTA SUTRADHAR, KAZI M. YASIN ARAFAT, JANNATUN NAYEEM and \\ M. SARWAR JAHAN \\ Pulp and Paper Research Division, BCSIR Laboratories, Dhaka, Dr. Qudrat-i-Khuda Road, \\ Dhaka 1205, Bangladesh \\ $\bowtie$ Corresponding author: M. Sarwar Jahan, sarwar2065@hotmail.com
}

Received December 1, 2019

Acetic acid/formic acid/water ( $\mathrm{AA} / \mathrm{FA} / \mathrm{H}_{2} \mathrm{O}, 50 / 40 / 10$ ratio) was used to fractionate rice straw into lignin, hemicellulosic sugars, silica and dissolving pulp. In this paper, lignin separated from rice straw was utilized in the preparation of lignin-phenol-formaldehyde resins. AA/FA/ $\mathrm{H}_{2} \mathrm{O}$ lignin was characterized as having lower molecular weight $\left(\mathrm{M}_{\mathrm{w}}\right)$, lower methoxyl group and higher phenolic hydroxyl group, which increased its reactivity. The methoxyl group per $\mathrm{C}_{9}$ unit was 0.87 and 0.75 for the rice straw lignin and the $\mathrm{AA} / \mathrm{FA} / \mathrm{H}_{2} \mathrm{O}$ spent liquor lignin, respectively. AA/FA/ $\mathrm{H}_{2} \mathrm{O}$ lignin-phenol-formaldehyde (LPF) resins were produced in one-step preparation, with different content of lignin. The formaldehyde/phenol mole ratio $(\mathrm{F} / \mathrm{P})$ was 2.0 and the $\mathrm{NaOH} /$ phenol mole ratios $(\mathrm{S} / \mathrm{P})$ were between 0.3 and 0.5 . The percentage of substitution of phenol by lignin was between 40 and $60 \%$. The shear strength of plywood was tested, and the plywood bonded with LPF resin showed comparable results to those of the phenol-formaldehyde bonded plywood. The results indicated that the substitution of $50 \%$ phenol by $\mathrm{AA} / \mathrm{FA} / \mathrm{H}_{2} \mathrm{O}$ lignin is feasible in the preparation of phenol-formaldehyde resin.

Keywords: organic acid lignin, methoxyl group, molecular weight, phenol-formaldehyde resin, shear strength

\section{INTRODUCTION}

Lignin is the second most abundant natural polymer, which is mostly isolated from biomass, such as wood, and agricultural residues, such as wheat straw, rice straw, bagasse etc. In pulping processes, lignin is dissolved in the cooking liquor. Traditionally, the black liquor lignin is burnt in pulp mills for power generation. The main challenges in using lignin for high value added products, such as chemicals and biomaterials, are its insolubility and complex polymer structure. ${ }^{1}$ Organosolv pulping is one of the sulphur free processes to cook non-wood plants, such as grasses, with various organic acids, ethanol, methanol etc. As the isolated lignin will be sulphur free, it can be considered as a promising perspective for future biorefineries. ${ }^{2}$

Phenol formaldehyde (PF) resins are used as adhesive for plywood, particleboard, hardboard etc. However, PF resin adhesives are not used extensively in interior applications because of the high price of phenol, which is derived from petroleum. Another factor that has downcast the use of $\mathrm{PF}$ resin adhesives is that exposure to phenol during the processes of adhesive synthesis and plywood production can be harmful to humans. It is time to reduce the use of petroleum based products and consequently reduce greenhouse gas emission. These limitations hamper the development of the PF resin industry. Therefore, there has been growing interest in finding low-cost and nontoxic alternatives to substitute phenol.

Alternative binders for wood composite panel products have been a subject of interest for the adhesive industry for many years. Extensive research has been done on the use of lignins to prepare wood adhesives. ${ }^{1-2}$ However, in spite of the large body of research on lignin utilization in wood adhesives, the record of its industrial use is poor. Most research has been carried out on substituting phenol by lignin to a certain extent in phenol-formaldehyde resin (PF) preparation. ${ }^{3-4}$ Also, researchers have been trying to improve the reactivity of lignin by methylation, phenolation and co-condensation with phenol. ${ }^{5}$ To utilize lignin as a raw material for adhesives, two main 
are used: firstly, by reducing the steric hindrance by hydrolytic or oxidative depolymerization, and secondly, by phenolation, demethoxylation and methylation of lignin. The first strategy involves increasing the accessibility of the reactive sites and the second strategy involves the introduction of reactive sites. $^{6}$ Considering the lignin monomer, an electrophilic addition between formaldehyde and free ortho positions of guaiacyl and p-hydroxyphenyl unit may occur. Tachon et $a l^{3}$ showed that organosolv wheat straw lignin could be used for up to $70 \%$ substitution of phenol in PF resol, without any chemical modification of lignin. The thermo-mechanical properties of the prepared resin were similar to those of the reference resin. In a study, it was observed that organic acid lignin has a high content phenolic hydroxyl groups, which facilitate reactivity in PF preparation. ${ }^{7}$ Recently, a biorefinery concept in dissolving pulp production from rice straw with an organic acid mixture was developed, where all the components of rice were fractionated efficiently. ${ }^{8}$

The main objective of this study was to use organic acid lignin from rice straw to replace part of phenol in preparing phenol formaldehyde resin and use it as binder for plywood. Organic acid and alkali lignins were characterized by FTIR, ${ }^{1} \mathrm{H}$ NMR, molecular weight determination, and elemental and methoxyl analyses. For comparison, the lignin isolated from rice straw by the acidic dioxane method was also characterized as mentioned above.

\section{EXPERIMENTAL \\ Materials}

Rice straw was collected from Mankgong district. All the chemicals were reagent grade and purchased from Sigma-Aldrich.

\section{Lignin extraction}

Rice straw was ground (40/60 mesh) in a Wiley mill, extracted with acetone and dried in vacuum over $\mathrm{P}_{2} \mathrm{O}_{5}$. The acetone extract free meals were refluxed with acidic dioxane solution $(9: 1)(\mathrm{v} / \mathrm{v})$. The lignin extraction method was described in detail elsewhere. ${ }^{6}$ The concentration of $\mathrm{HCl}$ in the dioxane solution was $0.2 \mathrm{~N}$. The dioxane to meal ratio was 8 . The ground rice straw meal was refluxed with dioxane solution for about 1 hour in $\mathrm{N}_{2}$ atm. The $\mathrm{N}_{2}$ flow was maintained at $50 \mathrm{~mm} / \mathrm{min}$. After completing the reflux time, the wood meal dioxane mixture was filtered in a Buckner funnel using filter no. 2 . The residue was washed with dioxane solution (9:1). The dioxane solution was then neutralized by adding solid $\mathrm{Na}_{2} \mathrm{CO}_{3}$ and filtered. The filtrate was concentrated in a vacuum evaporator at 40 ${ }^{\circ} \mathrm{C}$. Then, the concentrated dioxane solution was added dropwise to water to precipitate lignin. The lignin precipitate was washed and dried in vacuum over $\mathrm{P}_{2} \mathrm{O}_{5}$.

Dried crude lignin was dissolved in dioxane (9:1), and again precipitated in ether with constant stirring by a magnetic bar. The precipitated pure lignin was dried in vacuum over $\mathrm{P}_{2} \mathrm{O}_{5}$ and weighed.

\section{Rice straw delignification process}

The rice straw fractionation was widely described in our previous work. ${ }^{8} 50 \mathrm{~g}$ of rice straw was refluxed with the mixture of formic acid, acetic acid and water under the following conditions: formic acid/acetic acid/water (FA/AA/ $\left.\mathrm{H}_{2} \mathrm{O}\right)(\mathrm{V} / \mathrm{V})$ : 50/40/10, reaction time: 4 hours at boiling temperature, material to liquor ratio: $1: 8$.

\section{Alkaline extraction of rice straw pulp}

After separation of the spent liquor from the delignification step, the pulp fibres underwent the alkaline extraction process for further removal of lignin, hemicelluloses and silica. ${ }^{8}$ This process was carried out in a polyethylene bag with $8 \%$ sodium hydroxide at $25{ }^{\circ} \mathrm{C}$ for $2 \mathrm{~h}$. The consistency was $10 \%$. After extraction, the pulp fibres were filtered and the filtrate was collected for lignin and silica separation.

\section{Lignin isolation from spent liquor}

The lignin was dissolved during the delignification process with organic acid (AA/FA/ $\left.\mathrm{H}_{2} \mathrm{O}-50 / 40 / 10\right)$. It was precipitated from the concentrated organic acid spent liquor in five volumes of water. The residue was filtered in a Buchner funnel, washed with water and vacuum-dried over $\mathrm{P}_{2} \mathrm{O}_{5}$. The isolated lignin was purified by dissolution in dioxane (9:1) and precipitation in ether, followed by vacuum drying over $\mathrm{P}_{2} \mathrm{O}_{5}$. A part of the residual lignin was dissolved during the alkaline extraction of rice straw pulp. The lignin was precipitated by reducing the $\mathrm{pH}$ to 2 by adding $1 \mathrm{~N}$ $\mathrm{HCl}$, which was separated by centrifugation, followed by vacuum drying over $\mathrm{P}_{2} \mathrm{O}_{5}$. The dried crude lignin was dissolved in dioxane (9:1), and again precipitated in ether with constant stirring by a magnetic bar. The precipitated pure lignin was dried in vacuum over $\mathrm{P}_{2} \mathrm{O}_{5}$ and weighed.

\section{Lignin acetylation}

An amount of $100 \mathrm{mg}$ of lignin was added to 1.5 $\mathrm{mL}$ of dry pyridine-acetic anhydride $(1: 1)$, for $72 \mathrm{~h}$. The solution was added to a 10-fold volume of ice-cold water, whereupon the acetylated sample was recovered as a precipitate, which was purified by successive washing with water and dried under vacuum over $\mathrm{P}_{2} \mathrm{O}_{5}$.

\section{Elemental analysis}

$\mathrm{C}, \mathrm{H}, \mathrm{O}$ and $\mathrm{N}$ analyses were carried out in the Analytical Research Division, BCSIR. The methoxyl 
content in dioxane lignin was determined in accordance with the Zeisel-Viebock-Schwappach method:

Methoxy group, $\left[\mathrm{OCH}_{3}\right](\%)=\left[\left(\mathrm{a} * \mathrm{f}^{*} 0.5172\right) / \mathrm{A}\right] * 100$

where a - volume of $1 \mathrm{~N} \mathrm{Na}_{2} \mathrm{~S}_{2} \mathrm{O}_{3} ; \mathrm{f}$ - the titer factor for $0.1 \mathrm{~N} \mathrm{Na}_{2} \mathrm{~S}_{2} \mathrm{O}_{3} ; 0.5172$ - the quantity of $\mathrm{OCH}_{3}$ groups, corresponding to $1 \mathrm{~mL}$ of $0.1 \mathrm{~N} \mathrm{Na}_{2} \mathrm{~S}_{2} \mathrm{O}_{3}$; $\mathrm{A}-$ mg of lignin sample.

\section{FTIR spectroscopy}

Infrared spectra were recorded on a Shimadzu FTIR spectrometer model 8201PC. The dried samples were embedded in $\mathrm{KBr}$ pellets in a concentration of about $1 \mathrm{mg} / 100 \mathrm{mg} \mathrm{KBr}$. The spectra were recorded in the absorption band mode in the $4000-400 \mathrm{~cm}^{-1}$ range.

\section{${ }^{1}$ H NMR spectroscopy}

The spectra of the lignin solution $(100 \mathrm{mg}$ of acetylated lignin contained in $0.5 \mathrm{~mL} \mathrm{CDCl}_{3}$ ) were recorded on a Bruker 400 spectrometer. The solvent was used as internal standard (ppm 7.25). For quantification of protons, the signal in specified regions of the spectrum were integrated with respect to a spectrum-wide baseline drawn at the level of the background noise, and the results were referred to the signal for methoxyl protons, whose average number per $\mathrm{C}_{9}$ unit was established as described above.

\section{Molecular weight}

The weight average (Mw) and number average molecular (Mn) weight of acetylated dioxane, organic acid and alkali lignins were determined by GPC on a Sodex KF-802.5 column. The samples were dissolved in tetrahydrofuran (THF) and $10 \mu \mathrm{L}$ was injected. The column was operated at $30{ }^{\circ} \mathrm{C}$ and eluted with $\mathrm{THF}$ at a flow rate of $1 \mathrm{~mL} / \mathrm{min}$. The column was calibrated using polystyrene standards.

\section{Synthesis and characterization of lignin-phenol- formaldehyde resins}

The LPF resins in this study were synthesized in a three-neck flask, equipped with a magnetic stirrer, cooling condenser, thermometer, and water bath. ${ }^{9}$ $\mathrm{NaOH}$ was used to catalyze the reaction in a concentration of $6 \%$ of total reactant weight. In the first step, phenol and lignin were adequately mixed, the percentage of substitution of phenol by lignin was varied between 40 and $60 \%$. Then, the appropriate amount of $\mathrm{NaOH}$ solution $(30 \% \mathrm{wt})$ was added to adjust the $\mathrm{pH}$ value of the mixture to 10 . The $\mathrm{NaOH} /$ phenol mole ratio (S/P) between 0.3 to 0.5 and the formaldehyde/phenol mole ratio $(\mathrm{F} / \mathrm{P})$ was 2.0. This system was heated to $90{ }^{\circ} \mathrm{C}$ and held for $1 \mathrm{~h}$. After this step, the temperature of the resulted mixture was dropped to $80{ }^{\circ} \mathrm{C}$, and $70 \%$ of the total formaldehyde and $\mathrm{NaOH}$ solution $(30 \%$ wt) was added. The obtained mixture was kept at $80^{\circ} \mathrm{C}$ for $1 \mathrm{~h}$. Next, the remaining formaldehyde was added, and the mixture was kept at $80{ }^{\circ} \mathrm{C}$ for $1 \mathrm{~h}$. Finally, the temperature of the mixture was decreased to $65{ }^{\circ} \mathrm{C}$, and the remaining $\mathrm{NaOH}$ solution $(30 \% \mathrm{wt})$ and urea (5\% of the total weight of phenol and lignin) was added. This resulted mixture was held at $65{ }^{\circ} \mathrm{C}$ for 0.5 $\mathrm{h}$ to yield the LPF resin. The $\mathrm{pH}$ was measured at room temperature by a Fisherbrand $\mathrm{pH}$ meter. Viscosity was measured by a Brookfield viscometer by different spindles at certain rpm at room temperature.

\section{Plywood preparation and testing}

Veneer was obtained from Akij Particle Board Mills Ltd., and was made from Gurjan (Dipterocarpus turbinatus) wood. Two layer plywoods (400 $\mathrm{mm} \times 400$ $\mathrm{mm} \times 4.5 \mathrm{~mm})$ were prepared using the LPF resin adhesives. The core veneer was coated with 140-160 $\mathrm{g} / \mathrm{m}^{2}$ adhesive on each side. The coated veneers were hot-pressed at $145^{\circ} \mathrm{C}$ under $1.0 \mathrm{MPa}$ for $7.0 \mathrm{~min}$. The bond strength was measured according to the method described by Yang et al. ${ }^{10}$ in HK-10KN, Hounsefield, UK. The $\mathrm{pH}$, viscosity and solid content of the adhesives were determined according to the method described by Yang et al. ${ }^{7}$

\section{RESULTS AND DISCUSSION Proposed process concept}

A proposed biorefinery concept of dissolving pulp production from rice straw was described in our previous article ${ }^{8}$ where rice straw was treated with the organic acid mixture at the boiling temperature. Most of the lignin and hemicelluloses are dissolved in spent liquor without affecting $\alpha$-cellulose. Organic acid can be easily recovered from the spent liquor by evaporation. The solid residue is composed of lignin and hemicellulosic sugars (mono/oligo), which are separated by dissolving hemicelluloses in water. It was reported that organic acid spent liquor lignin from jute was characterized by high content of phenolics, ${ }^{7}$ which would facilitate its use in phenolic resin., ${ }^{3,11}$ Organic acid pulp was further treated with alkali, which dissolved more lignin, hemicelluloses and silica present in the fiber. Silica can be separated from the alkaline extracted liquor by reducing the $\mathrm{pH}$. The detailed biorefinery concept is presented in Figure 1. In this investigation, organic acid spent liquor lignin from the rice straw was used for substituting phenol in phenol-formaldehyde resin preparation.

\section{Elemental analysis and methoxyl content}

Chemical analyses and determination of methoxyl group and $\mathrm{C}_{9}$ atoms of dioxane lignin, organic acid lignin and alkaline extracted lignin were conducted and the results are shown in Table 1. As may be noted in Table 1, the nitrogen 
content in dioxane lignin from rice straw was higher, compared to that of other lignins. Nitrogen was mainly derived from the protein-lignin complexes formed during delignification. A very small difference was observed in $\mathrm{C}, \mathrm{H}, \mathrm{O}$ content, but the methoxyl content decreased with treatment. In the dioxane lignin, the methoxyl content was $12.78 \%$, which decreased to $11.53 \%$ upon acid treatment and further decreased to $9.41 \%$ upon alkaline extraction. This decrease indicated that oxidation and removal of $\mathrm{OCH}_{3}$ occurred during AA/FA/ $\mathrm{H}_{2} \mathrm{O}$ pulping. This also suggested that the acidity of the pulping medium facilitated the loss of methoxyl groups, similarly to the case of formic acid pulping of bamboo. ${ }^{12} \mathrm{Li}$ et al. ${ }^{12}$ also showed that the methoxyl contents in formic acid lignin were lower than that in MWL. The number of $\mathrm{OCH}_{3}$ decreased from $1.52 / \mathrm{C}_{9}$ in MWL to $1.29-1.32 / \mathrm{C}_{9}$ in formic acid lignin. The $\mathrm{C}_{9}$ formula of dioxane lignin from rice straw was $\mathrm{C}_{9} \mathrm{H}_{8.56} \mathrm{O}_{3.76}\left(\mathrm{OCH}_{3}\right)_{0.87}$, while for formic acid and alkali lignins it was $\mathrm{C}_{9} \mathrm{H}_{8.20} \mathrm{O}_{3.79}\left(\mathrm{OCH}_{3}\right)_{0.75}$ and $\mathrm{C}_{9} \mathrm{H}_{7.30} \mathrm{O}_{3.55}\left(\mathrm{OCH}_{3}\right)_{0.61}$, respectively. Demethylation of lignin increased the reactive sites, which was beneficial for resin preparation. ${ }^{13}$

\section{Fourier transform infrared (FTIR) spectroscopy}

As the functional groups and chemical bonds of the dioxane and organic acid lignin samples are important to understand the chemical structure of the isolated lignins, they were investigated by FTIR and shown in Figure 2. The characteristic absorption peaks were identified and attributed according to Faix. ${ }^{14}$

Both lignins exhibited a broad band at 3400 $\mathrm{cm}^{-1}$, which was due to the hydroxyl groups of aromatic and aliphatic structures. The bands at 2939 and $2849 \mathrm{~cm}^{-1}$ are due to $\mathrm{C}-\mathrm{H}$ stretching in the aromatic methoxyl group and methyl and methylene groups of the side chain. The strong band of the carbonyl group at $1720 \mathrm{~cm}^{-1}$ and the carbonyl group conjugated aromatic ring were found in both lignins. The bands at 1454 and 1420 $\mathrm{cm}^{-1}$ were attributed to the methoxyl groups, which were slightly stronger in the dioxane lignin than in the acid lignin. These results were consistent with the data on the methoxyl groups (Table 1).

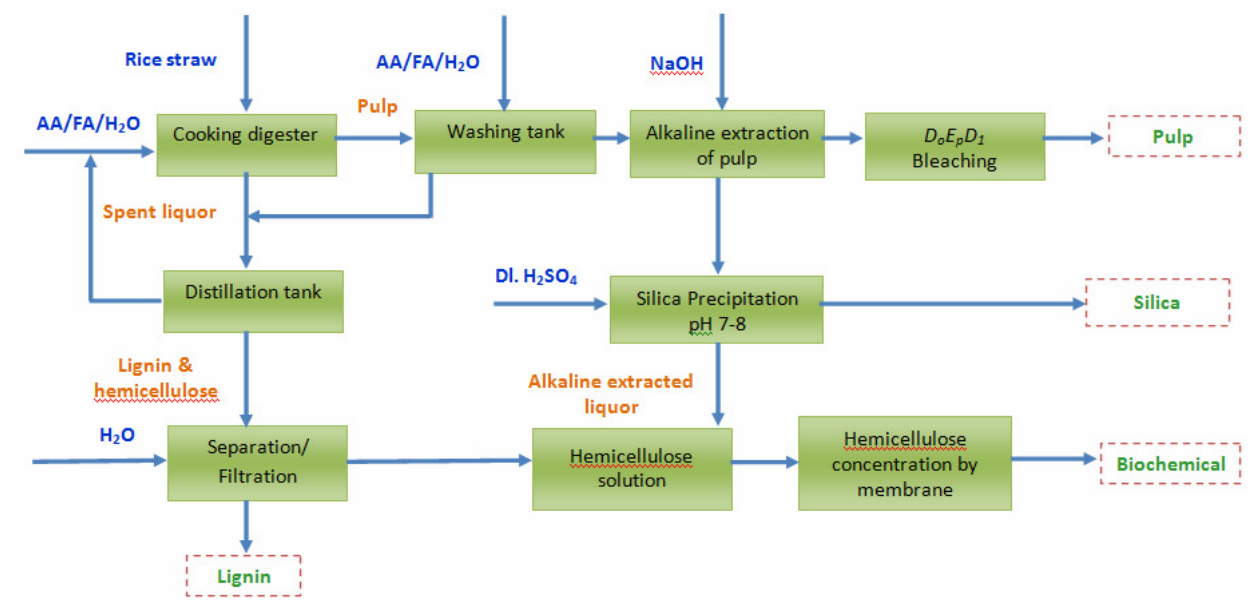

Figure 1: Organic acid based biorefinery scheme for dissolving pulp production

Table 1

Elemental analysis, methoxyl content and empirical formula of spent organic acid lignin

\begin{tabular}{lcccccc}
\hline Lignin sample & $\mathrm{C}$ & $\mathrm{H}$ & $\mathrm{N}$ & $\mathrm{O}$ & $\mathrm{OCH}_{3}$ & $\mathrm{C}_{9}$ Formula \\
\hline Rice straw (dioxane) & 56.34 & 5.31 & 3.1 & 35.25 & 12.78 & $\mathrm{C}_{9} \mathrm{H}_{8.56} \mathrm{O}_{3.76}\left(\mathrm{OCH}_{3}\right)_{0.87}$ \\
Acid treated & 57.86 & 5.17 & 1.01 & 35.96 & 11.53 & $\mathrm{C}_{9} \mathrm{H}_{8.20} \mathrm{O}_{3.79}\left(\mathrm{OCH}_{3}\right)_{0.75}$ \\
Alkali treated & 57.34 & 4.54 & 2.72 & 33.11 & 9.41 & $\mathrm{C}_{9} \mathrm{H}_{7.30} \mathrm{O}_{3.55}\left(\mathrm{OCH}_{3}\right)_{0.61}$ \\
\hline
\end{tabular}

*Empirical analysis formula $\mathrm{C}_{\mathrm{x}} \mathrm{H}_{\mathrm{y}} \mathrm{O}_{\mathrm{z}}\left(\mathrm{OCH}_{3}\right)_{\mathrm{n}}$ was calculated as follows: $\mathrm{n}=\left(\% \mathrm{OCH}_{3}\right) / 31.04 ; \mathrm{x}=(\% \mathrm{C}) / 12-\mathrm{n} ; \mathrm{y}=$ $(\% \mathrm{H})-3 \mathrm{n} ; \mathrm{z}=(\% \mathrm{O}) / 16-\mathrm{n}$ 


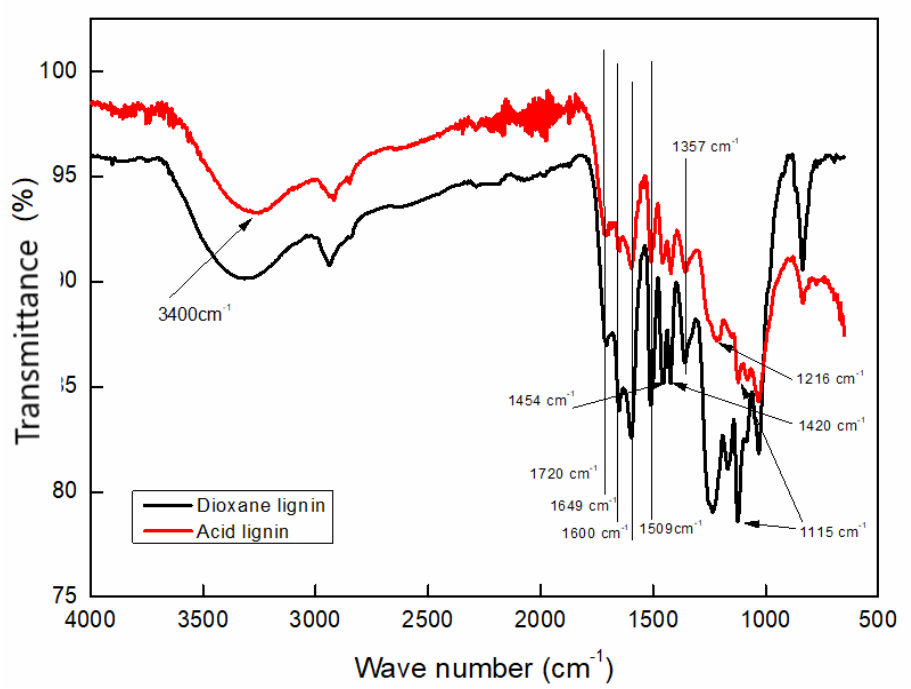

Figure 2: FT-IR spectra of dioxane and organic acid lignins

Both lignins showed aromatic skeletal characteristic bands at 1600, 1509 and $1422 \mathrm{~cm}^{-1}$. C-H deformations can be found at 1454-1460 $\mathrm{cm}^{-}$ ${ }^{1}$. The band at $1325 \mathrm{~cm}^{-1}$ is associated with the $\mathrm{C}=\mathrm{O}$ stretching of the syringyl structure in lignin molecules. The peak at $1216 \mathrm{~cm}^{-1}$ is assigned to the guaiacyl structure in lignin molecules, which is prominent in organic acid lignin. The out-ofplane $\mathrm{C}-\mathrm{H}$ bending of the syringyl content was observed at $833 \mathrm{~cm}^{-1}$. The $\mathrm{C}-\mathrm{H}$ stretch assigned to the syringyl rings is present at $1115 \mathrm{~cm}^{-1}$ in both lignins. The strong peaks at $1044-1030 \mathrm{~cm}^{-1}$ were found in both lignins, and were related to $\mathrm{C}=\mathrm{O}$ stretching of primary alcohols. There was a strong band at $1357 \mathrm{~cm}^{-1}$ corresponding to aliphatic alcohol and aliphatic $\mathrm{C}-\mathrm{H}$ in the methyl group, which was stronger in organic acid lignin, indicating that its $\beta-\mathrm{O}-4$ and $\alpha-\mathrm{O}-4$ linkages were cleaved, leaving a lot of non-etherified phenolic $\mathrm{OH}$ groups in the lignin. Organic acid delignification played an important role in the final structure of organic acid lignin. As compared to dioxane lignin, the decrease in peak intensity at $1654 \mathrm{~cm}^{-1}$ can be attributed to the carbonyl group stretch of conjugated p-substituted aryl ketones in organic acid lignin, indicating that this structure had been removed partly during organic acid delignification. ${ }^{15}$ Similar results were observed during kraft delignification. ${ }^{16}$

\section{Molecular weight}

The weight-average $(\mathrm{Mw})$ and numberaverage (Mn) molecular weights and polydispersity (Mw/Mn) of the two technical lignins (organic acid and alkali lignins) and dioxane lignin from rice straw are given in Table 2. The Mw molecular weight of dioxane lignin was $10574 \mathrm{~g} / \mathrm{mol}$, while those of organic acid and alkali lignins were only 3254 and $3658 \mathrm{~g} / \mathrm{mol}$, respectively. Li et al. ${ }^{12}$ also showed that formic acid lignins from bamboo had $\mathrm{Mw}$ ranging from 7300 to 10,020 and $\mathrm{Mn}$ ranging from 3840 to 4450 , which were lower than that of MWL of bamboo. Pizzi ${ }^{17}$ suggested that high-molecularweight lignin is beneficial in terms of synthesis time for LPF resin preparation. The addition of a high amount of lignin in the LPF synthesis disturbs the uniformity of the cured resin structure. ${ }^{18}$ The low-molecular-weight of organic acid lignin can be explained by the cleaved main internal linkages, compared with the macromolecular structure of native lignin; the cleavage introduces more active sites.

Table 2

Molecular weight of lignins

\begin{tabular}{lccc}
\hline Lignin sample & $\mathrm{Mw}\left(\mathrm{g} \cdot \mathrm{mol}^{-1}\right)$ & $\left.\mathrm{Mn}^{-1} \mathrm{~g} \cdot \mathrm{mol}^{-1}\right)$ & $\mathrm{Mw} / \mathrm{Mn}$ \\
\hline Dioxane & 10574 & 4468 & 2.37 \\
Organic acid & 3254 & 877 & 3.71 \\
Alkali & 3658 & 908 & 4.02 \\
\hline
\end{tabular}


Table 3

Assignments of signals and protons per $\mathrm{C}_{9}$ structural unit in ${ }^{1} \mathrm{H}$ NMR spectra of acetylated lignin

\begin{tabular}{llccc}
\hline \multirow{2}{*}{ Range ppm } & Main assignments & \multicolumn{3}{c}{ Proton per $\mathrm{C}_{9}$ unit } \\
\cline { 3 - 4 } & & Dioxane & Organic acid & Alkali \\
\hline $7.25-6.80$ & Aromatic proton in guaiacyl units & 0.35 & 0.32 & 0.32 \\
$6.80-6.25$ & Aromatic proton in syringyl units & 0.46 & 0.50 & 0.36 \\
$6.25-5.75$ & H $\alpha$ of $\beta-O-4$ and $\beta-1$ structures & 0.40 & 0.41 & 0.38 \\
$5.20-4.90$ & H of xylan residue & & & \\
$4.90-4.30$ & H $\alpha$ H $\beta$ of $\beta-O-4$ structures & 0.32 & 0.18 & 0.13 \\
& H $\alpha$ of $\beta-\beta$ structures & & & \\
$4.30-4.00$ & H of xylan residue & & & \\
$4.00-3.48$ & H of methoxyl groups & 2.61 & 2.25 & 0.83 \\
$2.50-2.22$ & H of aromatic acetates & 0.61 & 0.68 & 0.51 \\
$2.22-1.60$ & H of aliphatic acetates & 3.01 & 2.17 & 2.00 \\
\hline
\end{tabular}

\section{H $^{\mathbf{1}}$-NMR spectroscopy}

The chemical structure of acetylated lignin samples of dioxane, organic acid and alkali lignins was also studied using ${ }^{1} \mathrm{H}$ NMR spectrometry. As pointed out in Table 3 , the integral of all signals between 6.0 and $8.0 \mathrm{ppm}$ can be attributed to aromatic protons in syringyl $(\mathrm{S})$ and guaiacyl $(\mathrm{G})$ units. Methoxyl protons ($\mathrm{OCH}_{3}$ ), closely related to the G:S proportion, give an intense signal at $3.8 \mathrm{ppm}$.

\section{Hydroxyl groups}

Acetylation produces derivatives that display broad proton signals in regions with small interference with other hydrogen signals. In addition, aromatic and aliphatic acetyl groups shifted differently (2.3 and $2.1 \mathrm{ppm}$, respectively) giving rise to separate peaks. Thus, ${ }^{1} \mathrm{H}$ NMR spectrometry of acetylated lignin samples reveals both the total content of acetyl groups (proportional to $\mathrm{OH}$ content) and the ratio between aromatic and aliphatic substituent. ${ }^{19}$

The number of free aliphatic and phenolic hydroxyl groups per $\mathrm{C}_{9}$ unit was determined from the corresponding acetate signals. The proton of the aliphatic hydroxyl group of organic acid lignin from the spent liquor was lower and the aromatic hydroxyl group was higher than in the dioxane lignin isolated from rice straw. This result suggested that organic acid lignin would be more reactive than the original lignin from rice straw in the subsequent use in phenol formaldehyde or other resin preparation. The proton of the aliphatic and aromatic acetate group reached 3.01 and 0.61 for dioxane lignin, 2.17 and 0.68 for organic acid and 2.00 and 0.51 for alkali lignin, respectively. In a previous study, formic acid lignin showed higher ph-OH than acetic acid lignin. ${ }^{7}$ Sano et al..$^{20}$ observed that the content of alc- $\mathrm{OH}$ and ph-OH decreased with increasing the amount of acetic acid in the liquor. In proto lignin, the aliphatic hydroxyl was higher than the aromatic hydroxyl group. However, the lignin obtained from the spent liquor of formic or acetic acid had higher content of aromatic hydroxyl group than aliphatic hydroxyl group, which indicated the cleavage of $\beta-O-4$ bonds during organic acid pulping. Davis et al. ${ }^{21}$ showed that acetic acid cleaved the $\beta-O-4$ ether containing free phenolic units.

\section{Aromatic protons}

All the spectra show two peaks in the aromatic proton region, corresponding to the guaiacyl $(\delta$ $6.9)$ and syringyl units $(\delta$ 6.6). All the lignins showed both $\mathrm{G}$ and $\mathrm{S}$ units. The $\mathrm{G}$ and $\mathrm{S}$ type protons per $\mathrm{C}_{9}$ unit were 0.36 and 0.46 for dioxane lignin, 0.32 and 0.50 for organic acid lignin and 0.32 and 0.36 for alkali lignin, respectively. A clear signal between 7.3 and 7.6 $\mathrm{ppm}$ is assigned to the aromatic protons of $p$ coumaric acid and ferulic acid, usually found in non-wood lignins, such as grass lignin.

\section{$\beta-O-4$ structure}

The aryl glycerol $\beta-O-4$ aryl ether linkage constitutes the main intermonomeric connection in lignin. ${ }^{19}$ NMR spectra show that the structural element of these lignins may contain both erythro and threo configurations due to the presence of proton at the $\mathrm{C}-\alpha$ position of the side chain. The erythro protons $(\mathrm{H} \alpha)$ give a stronger peak at 6.01 $\mathrm{ppm}$ than the corresponding peak for thero form at $\delta 6.09$ in all the lignins.

\section{Lignin-phenol-formaldehyde (LPF)}

Figure 3 presents the proposed reaction during the synthesis of the resin. $\mathrm{NaOH}$ acts as catalyst, 
which facilitates the condensation reaction by activating the lignin hydroxyl group to link with the formaldehyde. Having lower methoxyl content per $\mathrm{C}_{9}$ unit and lower molecular weight, the organic acid treated rice straw lignin had more active sites to react with formaldehyde and eventually form crosslinks with urea as well.

The prepared LPF resin adhesives using organic acid lignin were dark-brown aqueous solutions with satisfactory water solubility. As shown in Table 4, the viscosity increased with the addition of lignin, which can be explained by the colloidal nature of the high-molecular-weight lignin in alkaline solution. The viscosity of LPF resin adhesives was similar to that obtained for biorefinery technical lignin and higher than that of the commercial phenol-formaldehyde resin adhesive. ${ }^{7}$ Highly viscous resin products can be difficult to effectively utilize in the plywood industry. As the prepared LPF resin was soluble in water, so the viscosity can be readily adjustable. The addition of lignin increased the solid content of the prepared resin. Higher solid content may facilitate the formation of a continuous bond line between the two cementing limiting surfaces. Another important parameter of phenol formaldehyde resin is the alkaline $\mathrm{pH}$ range - the $\mathrm{pH}$ of our final resin was kept around 10.5. An earlier research showed that the presence of alkali increases the hygroscopicity and enhances the time dependent creep of PF resins due to the plasticisation of the adhesive. The PF resins with a high $\mathrm{pH}$ have great potential to develop delayed elastic creep. ${ }^{22}$

The shear strength values of the plywood bonded using LPF resin adhesives are presented in Table 4. Plywood specimens were attached to each other using the adhesives and hot pressed at $145^{\circ} \mathrm{C}$ for curing. During curing, the crosslinking occurred among the active functional groups of lignin, formaldehyde and urea.
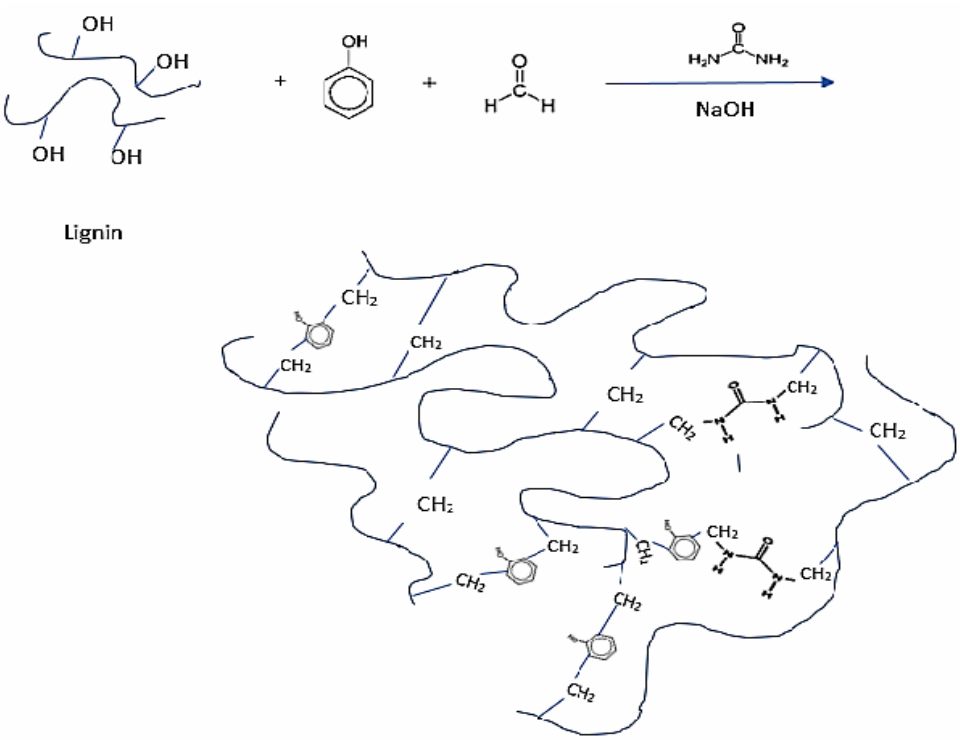

Figure 3: Proposed crosslinked structure of LPF

Table 4

Performance of lignin substitution in phenol-formaldehyde resin

\begin{tabular}{ccccc}
\hline Lignin substitution (\%) & $\mathrm{pH}$ & Solid content & Viscosity (mPa.s) & Shear strength (MPa) \\
\hline 0 & 11.06 & 45.33 & 1356 & 8.37 \\
40 & 10.65 & 48.91 & 1824 & 8.02 \\
50 & 10.32 & 50.06 & 1890 & 7.99 \\
60 & 10.06 & 51.43 & 1956 & 7.81 \\
\hline
\end{tabular}


It was observed that the strength of our prepared resin was almost similar to that of the PF resin, which indicated that the organic acid lignin was similarly reactive to phenol, due to its lower Mw. Moreover, the addition of urea in the resin preparation accelerated the crosslinking reactions, forming additional structures and a complex composition, which led the final resin with such strength. Evidence has been found of the forming $\mathrm{Ph}-\mathrm{CH}_{2}$-Urea linkages during phenol-ureaformaldehyde resin synthesis. ${ }^{23}$ Similarly, Zhang et $a l^{24}{ }^{24}$ crosslinked corn stalk lignin with furfuryl alcohol-formaldehyde (FF) resin in the laboratory and produced good quality lignin-furfurylformaldehyde (LFF) resin. The $-\mathrm{CH}-(\mathrm{OH})$ groups were involved in the crosslinking of the LFF adhesive.

Many studies on preparing lignin based phenol formaldehyde resins have been carried out. However, most of the resins were prepared from kraft lignin or soda lignin, which had a high number average molecular weight and less active sites to react with formaldehyde. In contrast, in this research work, after fractionating the rice straw with a mixture of organic acid, we attempted to utilize the lower molecular weight acid lignin. A lignin based phenol-ureaformaldehyde resin was produced and applied to bond plywood specimens, leading to satisfactory tensile strength, compared to that achieved using commercial phenol-formaldehyde resin.

\section{CONCLUSION}

Organic acid allows efficient fractionation of rice straw into its components. Fractionated organic acid lignin had lower methoxyl content and higher phenolic hydroxyl content, as compared to the original rice straw lignin, which subsequently helped out in replacing phenol in phenol-formaldehyde resin preparation. Organic acid lignin was characterized as having lower molecular weight and higher polydispersity. The $G$ and $S$ type protons per $C_{9}$ unit were 0.36 and 0.46 for dioxane lignin, and 0.32 and 0.50 for organic acid lignin. Phenol was replaced by organic acid lignin in LPF resin preparation and the prepared LPF was used to bond plywood. The shear strength of the plywood bonded using LPF resin adhesives was almost similar that achieved in the case of PF resin, which indicated that the organic acid lignin was similarly reactive to phenol.
ACKNOWLEDGEMENT: Authors wish to thank the Ministry of Science and Technology, Bangladesh Government, BCSIR and University Grant Commission of Bangladesh, for financial assistance in carrying out the research.

\section{REFERENCES}

1 A. Gani and I. Naruse, Renew. Energ., 32, 649 (2007), https://doi.org/10.1016/j.renene.2006.02.017

2 K. Barta, T. D. Matson, M. L. Fettig, S. L. Scott, A. V. Iretskii et al., Green Chem., 12, 1640 (2010)

3 N. Tachon, B. Benjelloun-Mlayah and M. Delmas, BioResources, 11, $5797 \quad$ (2016), https://ojs.cnr.ncsu.edu/index.php/BioRes/article/view/ BioRes_11_3_5797_Tachon_Organosolv_Lignin_Phe nol_Substitute

4 M. Wang, M. Leitch and C. C. Xu, Eur. Polym. J., 45, 3380

(2009),

https://doi.org/10.1016/j.eurpolymj.2009.10.003

5 N. E. E. Mansouri, A. Pizzi and J. Salvado, J. Appl. Polym. Sci., 103, $1690 \quad$ (2007), https://doi.org/10.1002/app.25098

6 C. Xu, S. Cheng, Z. Yuan, M. Leitch and M. Anderson, in: "Lignin: Properties and Applications in Biotechnology and Bioenergy", edited by R. J. Paterson, Nova Science Publishers, Inc., New York, NY, USA, 2012, pp. 183-210

7 M. S. Jahan D. N. Chowdhury, M. K. Islam and M. S. Islam, Cellulose Chem. Technol., 41, 137 (2007), http://www.cellulosechemtechnol.ro/onlinearticles.php 8 M. S. Jahan, M. M. Rahman, S. Sutradhar and M. A. Quaiyyum, Nord. Pulp Pap. Res. J., 30, 562 (2015), https://doi.org/10.3183/npprj-2015-30-04-p562-567

9 B. Pang, S. Yang, W. Fang, T. Q. Yuan, D. S. Argyropoulos et al., Ind. Crop. Prod., 108, 316 (2017), https://doi.org/10.1016/j.indcrop.2017.07.009

10 J. H. Lora and W. G. Glasser, J. Polym. Environ., 10, 39

(2002),

https://doi.org/10.1023/A:1021070006895

${ }_{11}$ S. Yang, J. Q. Wu, Y. Zhang, T. Q. Yuan and R. C. Sun, J. Biobased Mater. Bio., 9, 266 (2015), https://doi.org/10.1166/jbmb.2015.1514

12 M. F. Li, S. N. Sun, F. Xu and R. C. Sun, Chem. $\begin{array}{llll}\text { Eng. } & \text { J., } & \text { 179, } & 80\end{array}$ https://doi.org/10.1016/j.cej.2011.10.060

13 F. Wang, J. Kuai, H. Pan, N. Wang and X. Zhu, Wood Sci. Technol., 52, $1343 \quad$ (2018), https://doi.org/10.1007/s00226-018-1024-z

14 O. Faix, in "Methods in Lignin Chemistry", edited by E. S. Lin and C. W. Dence, Springer, Berlin, 1992, pp. 83-109, https://doi.org/10.1007/978-3-642-74065$7-7$

${ }^{15}$ Y. Zhang, M. Qin, W. Xu, Y. Fu, Z. Wang et al., Ind. Crop. Prod., 115, $194 \quad$ (2018), https://doi.org/10.1016/j.indcrop.2018.02.025

16 A. Tejado, C. Pena, J. Labidi, J. M. Echeverria and I. Mondragon, Bioresour. Technol., 98, 1655 (2007), https://doi.org/10.1016/j.biortech.2006.05.042 
17 A. Pizzi, J. Adhes. Sci. Technol., 20, 829 (2006), https://doi.org/10.1163/156856106777638635

18 S. Yang, J. L. Wen, T. Q. Yuan and R. C. Sun, RSC Adv., 4 , 57996

(2014)

https://doi.org/10.1039/C4RA09595B

19 W. G. Glasser and R. K. Jain, Holzforschung, 47, 225 (1993), https://doi.org/10.1515/hfsg.1993.47.3.225

20 Y. Sano, M. Endo and Y. Sakashita, Journal of the Japan Wood Research Society (Japan), 35, 804 (1989)

21 J. L. Davis, F. Nakatsubo, K. Murakami and T. Umezawa, Journal of the Japan Wood Research Society (Japan), 33, 478 (1987)
22 F. H. Wang and Y. C. Hu, J. Cent. South. Univ. T., 14, 306 (2007), https://doi.org/10.1007/s11771-0070270-2

23 D.-B. Fan, G.-Y. Li, T.-F. Qin and F.-X. Chu, Polymers, $\quad$ 6, $2221 \quad$ (2014), https://doi.org/doi:10.3390/polym6082221

24 J. Zhang, X. Xi, X. Zhou, J. Liang, G. Du et al., Cellulose Chem. Technol., 53, 449 (2019), https://doi.org/10.35812/CelluloseChemTechnol.2019. 53.45 